\title{
Clampless technique during coronary artery bypass grafting for proximal anastomoses in the hostile aorta
}

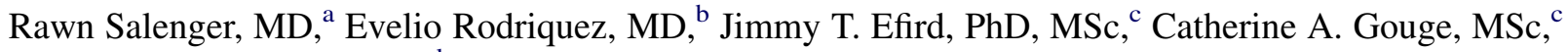 \\ Paolo Trubiano, MD, MBA, ${ }^{\mathrm{d}}$ and Edward F. Lundy, MD, $\mathrm{PhD}^{\mathrm{a}}$
}

\begin{abstract}
Objective: The incidence of stroke in patients undergoing coronary artery bypass grafting increases sharply in the face of significant atherosclerotic disease of the ascending aorta. We use a technique that allows full revascularization for this cohort of patients, while minimizing cerebral embolic risk.
\end{abstract}

\begin{abstract}
Methods: Intraoperative epiaortic ultrasound was used to screen for moderate or severe atherosclerotic disease of the ascending aorta and to precisely identify safe areas for cannulation and proximal anastomoses. By using a mildly hypothermic fibrillating technique, distal revascularization was then performed without clamping the aorta. Proximal anastomoses were accomplished under brief periods of circulatory arrest.
\end{abstract}

\begin{abstract}
Results: We routinely use this technique and examined our results in 71 consecutive patients found to have grade 3 or greater atherosclerotic plaque of the ascending aorta. This represented approximately $10.0 \%$ of our total population who underwent coronary artery bypass grafting over a 32-month period from January 2007 to September 2009. One patient $(1.4 \%)$ had a mild stroke that resolved, and there were no other neurologic complications.
\end{abstract}

Conclusions: We have found that clampless fibrillating heart surgery with circulatory arrest for proximal anastomoses is a safe and effective technique for revascularizing patients with significant ascending aortic disease who are at high risk for cerebral embolic complications. (J Thorac Cardiovasc Surg 2013;145:1584-8)

The incidence of stroke in patients undergoing routine coronary artery bypass grafting $(\mathrm{CABG})$ is reported to be $1.5 \%$, most commonly as a result of ascending aortic embolic phenomena. However, in the presence of significant ascending aortic atheromatous disease, this number has been shown to range from $9 \%$ to $15 \%$ or greater. ${ }^{1-6}$ This sharp increase in neurologic complications with ascending aortic disease represents a devastation for patients and is an increasing problem as older patients with greater comorbidities undergo operations. Numerous studies from centers worldwide have documented that stroke risk after coronary surgery is directly proportional to the atheromatous burden of the ascending aorta. ${ }^{1-6}$ These reports suggest that the most important element in preventing strokes in this population is avoiding atheroembolic phenomena during surgery. Off-pump

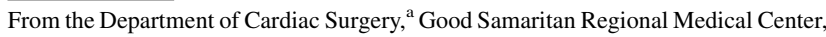
Suffern, NY; Department of Cardiac Surgery, ${ }^{\mathrm{b}}$ Saint Thomas Heart Hospital, Nashville, Tenn; Epidemiology \& Outcomes Research Unit, ${ }^{\mathrm{c}}$ East Carolina Heart Institute, Greenville, NC; and Cardiac Anesthesia, ${ }^{\mathrm{d}}$ Good Samaritan Regional Medical Center, Suffern, NY.

Disclosures: Authors have nothing to disclose with regard to commercial support.

Presented as an electronic poster at the 2010 Aortic Symposium New York, NY, April 29-30, 2010.

Received for publication Feb 27, 2012; revisions received April 9, 2012; accepted for publication May 16, 2012; available ahead of print June 18, 2012.

Address for reprints: Rawn Salenger, MD, Good Samaritan Regional Medical Center, Department of Cardiac Surgery, 257 Lafayette Ave, Ste 330, Suffern, NY 10901

(E-mail: rawn_salenger@bshsi.org).

$0022-5223 / \$ 36.00$

Copyright (c) 2013 by The American Association for Thoracic Surgery doi:10.1016/j.jtcvs.2012.05.045 surgery has been suggested as a solution but still often requires manipulation of the ascending aorta for proximal anastomoses or, possibly, incomplete revascularization. At Good Samaritan Regional Medical Center, intraoperative epiaortic ultrasound is used routinely to screen for moderate or severe atherosclerotic disease of the ascending aorta and to precisely identify safe areas for cannulation and proximal anastomoses. In patients with grade 3 or greater ascending aortic plaque, we then use cardiopulmonary bypass and brief episodes of circulatory arrest to perform CABG without clamping the aorta. This technique can provide full revascularization while minimizing cerebral embolic risk.

\section{PATIENTS AND METHODS}

After obtaining institutional review board exemption, we reviewed the records of 686 patients undergoing first-time isolated CABG from January 2007 to September 2009. Of these, 71 patients were found to have grade 3 or greater atherosclerotic plaque of the ascending aorta during routine intraoperative epiaortic ultrasound examination. There are numerous grading systems proposed for aortic atheroma evaluated by echocardiogram. We follow the grading system proposed by Katz and colleagues ${ }^{4}$ (Table 1). Epiaortic ultrasound also served to precisely identify safe areas for cannulation and proximal anastomoses.

We routinely perform $\mathrm{CABG}$ using mildly hypothermic $\left(30^{\circ} \mathrm{C}-32^{\circ} \mathrm{C}\right)$ noncardioplegic myocardial preservation with elective ventricular fibrillation. This technique, although not common, has been published and documented to provide excellent patient outcomes by several well-known sources. ${ }^{7-10}$ Distal anastomoses are constructed with intermittent aortic crossclamping or local vessel control. Proximal anastomoses are routinely performed with a partial side-biting clamp after epiaortic ultrasound demonstrates no significant atheromatous disease of the ascending aorta. For the 71 patients found to have grade 3 or greater atheromatous 

Abbreviations and Acronyms
$\mathrm{CABG}=$ coronary artery bypass grafting
$\mathrm{HCA}=$ hypothermic circulatory arrest
$\mathrm{OPCAB}=$ off-pump coronary artery bypass

plaque in the ascending aorta, no crossclamp or partial clamp was placed. Distal anastomoses were constructed with local vessel control, and proximal anastomoses were then constructed under brief periods of circulatory arrest at a temperature of $30^{\circ} \mathrm{C}$ to $32^{\circ} \mathrm{C}$. Mean arrest time was 5 minutes per anastomosis. If more than 1 proximal anastomosis was needed, staged intermittent periods of circulatory arrest were used. In no case were more than 2 brief episodes of circulatory arrest performed. If necessary, sequential grafts, or Y-grafting was used to achieve complete revascularization.

Data were analyzed using SAS version 9.2 (SAS Institute Inc, Cary, NC) and the Patient Analysis and Tracking System software program, version 6.0 (Axis Clinical Software Inc, Portland, Ore). Group differences between study variables were examined using 2-sample $t$ tests (continuous variables) and Fisher exact test (categoric variables) methods. Multivariable log-normal plots were used to assess underlying normality and heteroskedasticity of the data. When appropriate, a normalizing or variance stabilizing transformation was applied to the data. Statistical tests were 2-sided.

\section{RESULTS}

Patients requiring circulatory arrest were found to be statistically significantly older and more likely to have peripheral arterial disease, hypertension, and chronic obstructive pulmonary disease (Table 2). Of note, the number of patients with a history of cerebrovascular disease was similar for both the hypothermic circulatory arrest (HCA) and nonHCA groups, $15 \%$ versus $11 \%$.

The operative details for patients who underwent circulatory arrest compared with all other patients who underwent coronary bypass are listed in Table 3 . The mean number of grafts performed per patient was $3 \pm 0.1$ for both the HCA group and the general CABG group. In the HCA group, all major vessels that we intended to graft on the basis of the preoperative coronary angiogram were successfully grafted. Table 4 compares the operative outcomes for the 2 groups. There were 2 mortalities in the HCA group $(3 \%)$ that were unrelated to the circulatory arrest technique. One patient was an 80-year-old man with an ejection fraction of $15 \%$ who was taken to the operating room on an emergency basis during a ST-segment elevation myocardial infarction and who experienced persistent cardiac failure postoperatively. The other patient died of cardiac tamponade after removal of pacing wires. He died despite emergency bedside reexploration. The mortality for patients undergoing CABG who required HCA was nonsignificantly higher than in the non-HCA group $(2.82 \%$ vs $0.98 \%)$. There was 1 nondisabling stroke in the HCA group $(1.5 \%)$ and 1 nondisabling stroke in the non-HCA group $(0.2 \%)$. There were no transient ischemic attacks in the HCA group and 1 transient ischemic attack in the nonHCA group. The neurologic deficit for the patient in the
HCA group who experienced a stroke consisted of mild right upper-extremity weakness, which resolved completely shortly after discharge. Reexploration for bleeding was $3 \%$, which was higher than for the non-HCA population $(0.7 \%)$. However, this result was not statistically significant. All other complication rates were low and did not differ from the overall CABG population.

\section{DISCUSSION}

Our series suggests that the fibrillating technique with brief episodes of circulatory arrest for proximal anastomoses is a safe alternative for performing coronary surgery in patients with significant atherosclerotic disease of the ascending aorta. Our stroke rate of $1.4 \%$ compares favorably with the literature, which reports a $9 \%$ to $15 \%$ incidence of postoperative strokes for this high-risk group. Magnetic resonance imaging in our patient who had a stroke revealed a small left pontine infarct. An embolic cause could not be excluded, and this underscores that our technique likely reduces, but does not eliminate, the embolic risk in these hostile aortas. Minimizing stroke risk is critical for surgeons to maintain excellent outcomes and is a key factor in counseling patients who may have an option between percutaneous coronary intervention and CABG. Cardiac surgeons face the challenge of performing revascularization in progressively older patients with increasing atheromatous burden without releasing cerebral emboli. Standard techniques for performing $\mathrm{CABG}$, with cardioplegia and aortic crossclamping, expose these patients to a high risk of neurologic injury.

One of the fundamental concepts behind our technique is that of screening for diseased portions of the ascending aorta and then avoiding manipulation of those areas to decrease stroke rates. Other groups have investigated varied methods of identifying high-risk aortas. Methods such as intraoperative digital palpation or selective ultrasound based on preoperative patient risk factors, however, have been shown to be inadequate for identifying all ascending aortic atheroma. ${ }^{4,5,11-15}$ Preoperative computed axial tomography scanning has been used to screen for potential embolic material in the ascending aorta but may be limited to identifying calcified plaques. ${ }^{11}$ In our experience, some of the most advanced atheromatous disease is soft and noncalcified. This plaque is easily demonstrated and graded with intraoperative epiaortic ultrasound (Figure 1). Because other methods have failed to reliably rule out ascending aortic atheroma, we think that screening each patient's aorta with epiaortic ultrasound in the operating room is essential.

According to Kouchoukos and colleagues, ${ }^{16}$ simply modifying the locations of the crossclamp and sites for proximal anastomoses after identifying aortic atheroma still results in a significant stroke rate. ${ }^{16}$ This is likely due to the large area of aorta, which is directly or indirectly affected by the aortic crossclamp. Historically, multiple other options have been 
TABLE 1. Grading system for aortic atheroma

\begin{tabular}{ll}
\hline Grade & \multicolumn{1}{c}{ Description } \\
\hline I & Normal to mild intimal thickening \\
II & Severe intimal thickening without protruding atheroma \\
III & Atheroma protruding $<5 \mathrm{~mm}$ into lumen \\
IV & Atheroma protruding $\geq 5 \mathrm{~mm}$ into lumen \\
V & Any thickness with mobile component \\
\hline
\end{tabular}

proposed. The technique of aortic endarterectomy has been evaluated and proven ineffective in decreasing neurologic complications. ${ }^{17}$ For the most severely diseased ascending aorta, Rokkas and Kouchoukos ${ }^{17}$ have performed ascending aortic replacement with acceptable results. However, even with this technique, the stroke rate was $4.9 \%$ and the mortality rate was $8.6 \%$.

A more recent approach used by some has been off-pump coronary artery bypass (OPCAB) with all arterial revascularization and no proximal anastomoses. A series of 41 patients with severe atherosclerotic aortic disease treated in this manner was published. ${ }^{18}$ None of these patients experienced perioperative neurologic complications, and the mortality was $2.4 \%$. Unfortunately, the number of grafts per patient was 1.6, and many patients were incompletely revascularized. The group from the Montreal Heart Institute also published a report on a series of patients with no strokes who were treated with a no-touch, off-pump technique. However, the authors did not limit their use of this technique to a cohort of patients with significant ascending aortic atheroma. ${ }^{19}$ Questions regarding the long-term patency, completeness of revascularization, and discomfort of many surgeons with off-pump techniques may limit the applicability of this approach. Also, patients with hostile ascending aortas commonly have poor distal targets, which make them incrementally more difficult to revascularize off-pump.

On-pump beating heart surgery allows surgeons to perform distal anastomoses easily. Similar to off-pump surgery, this approach avoids an aortic crossclamp but still requires

TABLE 2. Preoperative characteristics

\begin{tabular}{lccc}
\hline & $\begin{array}{c}\text { HCA } \\
\mathbf{n = 7 1} \\
\text { Characteristics }\end{array}$ & $\begin{array}{c}\text { NO HCA } \\
\mathbf{n}=\mathbf{6 1 5} \\
\mathbf{n}(\%)\end{array}$ & $\begin{array}{c}\text { Post hoc } \\
\text { significance* }\end{array}$ \\
\hline Age (mean y) & $72 \pm 7.9$ & $65 \pm 10$ & $\S$ \\
Congestive heart failure & $18(25)$ & $98(16)$ & $\dagger$ \\
Left main disease & $34(48)$ & $240(39)$ & NS \\
Hypertension & $62(87)$ & $466(76)$ & $\ddagger$ \\
Diabetes mellitus & $33(46)$ & $247(40)$ & NS \\
COPD & $22(31)$ & $103(17)$ & $\S$ \\
PAD & $27(38)$ & $94(15)$ & $\S$ \\
Cerebrovascular disease & $11(16)$ & $65(11)$ & NS \\
Creatinine & $1.1 \pm 0.5$ & $1.2 \pm 0.9$ & NS \\
\hline
\end{tabular}

$H C A$, Hypothermic circulatory arrest; $C O P D$, chronic obstructive pulmonary disease; $P A D$, peripheral arterial disease; $N S$, not significant. $*$ Two-sample $t$ test for continuous variables; Fisher exact test for noncontinuous variables. $\dagger P \leq .10$. $¥ P \leq .05$. $\S P \leq .01 . \mathrm{NS}=P \geq .10$.
TABLE 3. Operative details

\begin{tabular}{lccc}
\hline & $\begin{array}{c}\text { HCA } \\
\mathbf{n}=\mathbf{7 1} \\
\text { Opean } \pm \text { SD }\end{array}$ & $\begin{array}{c}\text { No HCA } \\
\mathbf{n}=\mathbf{6 1 5} \\
\text { mean } \pm \text { SD }\end{array}$ & $\begin{array}{c}\text { Post hoc } \\
\text { significance* }\end{array}$ \\
\hline No. of distal arteries & $2.9 \pm 0.1$ & $2.9 \pm 0.1$ & NS \\
HCA time (mean min) & $5 \pm 1.0$ & - & - \\
CPB time (mean min) & $121 \pm 42$ & $120 \pm 38$ & NS \\
Crossclamp time (mean min) & - & $16 \pm 11$ & - \\
\hline$H C A$, Hypothermic circulatory arrest; $S D$, standard deviation; $C P B$, cardiopulmonary \\
bypass; $N S$, not significant. *Two-sample $t$ test for continuous variables; Fisher exact \\
test for noncontinuous variables. NS $=P \geq .10$.
\end{tabular}

a solution for constructing proximal anastomoses. Using bilateral pedicled internal thoracic arteries is sometimes a solution but not always technically feasible depending on the patient's anatomy. In addition, whether harvesting both internal thoracic arteries in certain subsets of patients is advisable remains controversial. We minimize the use of Y-grafting with the left internal thoracic artery as the sole source of inflow because of technical complexity, as well as concerns regarding long-term patency and adequacy of flow. $^{20-23}$ For surgeons who routinely use the Y-graft technique with good results, however, this may prove to be an acceptable option. ${ }^{24,25}$

One aspect of off-pump surgery that may allow safe proximal anastomosis construction is the HEARTSTRING Proximal Seal System (MAQUET Cardiovascular, Wayne, $\mathrm{NJ})$. Hilker and colleagues ${ }^{26}$ reported on 412 consecutive patients undergoing 542 proximal anastomoses with the HEARTSTRING device during OPCAB. Their stroke rate was only $0.48 \%$. In addition, Emmert and colleagues ${ }^{27}$ showed a lower incidence of stroke using OPCAB and the HEARTSTRING device compared with on-pump coronary surgery or OPCAB with partial clamping of the aorta. Unfortunately, both studies relied on digital palpation, not epiaortic ultrasound, to assess ascending aortic atheromatous disease. Therefore, the true severity of ascending aortic disease was unknown. In addition, the report from Emmert and

TABLE 4. Complications

\begin{tabular}{lccc}
\hline \multicolumn{1}{c}{ Complications } & $\begin{array}{c}\text { HCA } \\
\mathbf{n}=\mathbf{7 1} \\
\mathbf{n}(\%)\end{array}$ & $\begin{array}{c}\text { NO HCA } \\
\mathbf{n = 6 1 5} \\
\mathbf{n}(\%)\end{array}$ & $\begin{array}{c}\text { Post hoc } \\
\text { significance* }\end{array}$ \\
\hline Myocardial infarction & 0 & 0 & NS \\
30-d mortality & $2(2.8)$ & $6(1)$ & NS \\
Cerebrovascular attack & $1(1.4)$ & $3(0.5)$ & NS \\
Transient ischemic attack & 0 & $1(0.2)$ & NS \\
Reoperative bleeding & $2(2.8)$ & $4(0.7)$ & NS \\
Prolonged mechanical ventilation & $8(11.3)$ & $49(8)$ & NS \\
Mediastinitis & 0 & $1(0.2)$ & NS \\
Renal failure & 0 & $5(0.8)$ & NS \\
ICU length of stay (mean h) & $82 \pm 50$ & $80 \pm 77$ & NS \\
\hline
\end{tabular}

$H C A$, Hypothermic circulatory arrest; $I C U$, intensive care unit; $N S$, not significant. *Two-sample $t$ test for continuous variables; Fisher exact test for noncontinuous variables. NS $=P \geq .10$. 


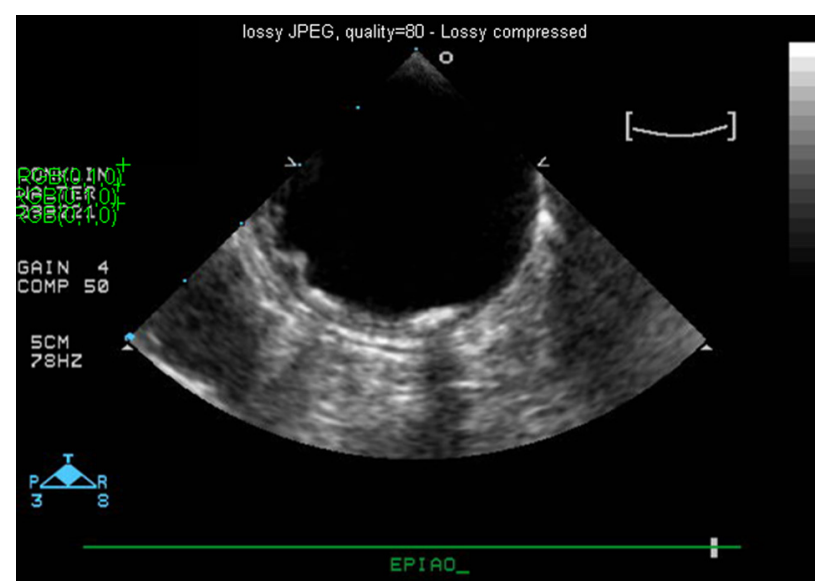

FIGURE 1. Intraoperative epiaortic sonography of the ascending aorta revealing grade 4 atherosclerotic plaque.

colleagues involves numerous surgeons selecting patients for different operative strategies on the basis of personal judgment. In this nonrandomized review, every outcome analyzed was superior in the OPCAB group. This is not consistent with randomized trials of off-pump versus on-pump surgery and raises the question as to whether the surgeons performing off-pump surgery just have better results at this center. ${ }^{27}$ The HEARTSTRING device may prove to be a useful option because it avoids aortic clamping, can be used in the diseased aorta, and does not require circulatory arrest. ${ }^{28}$ Using this anastomotic device does incur an extra cost of approximately $\$ 500$ per anastomosis. In addition, the question remains whether deploying this device inside a severely diseased aorta will liberate embolic debris. Future studies, specifically in patients with high aortic atheromatous burden, may help clarify this issue.

We believe that our approach to patients with moderate to severe atheromatous disease of the ascending aorta is a safe option that allows complete revascularization with minimal embolic risk. If no safe area can be found for cannulation, axillary cannulation can be used. With the placement of a left ventricular vent and local vessel control, fibrillating coronary surgery is similar to the operating conditions with which most surgeons are familiar. The ischemic time for the myocardium of 5 minutes during circulatory arrest is less than most ischemic intervals, during intermittent crossclamping, using the noncardioplegic technique. In fact, several well-known surgeons have described a similar approach to the hostile aorta with outstanding results. ${ }^{7-9}$ As with any technique, there are several technical points that must be emphasized to ensure the safe conduct of fibrillating heart surgery. These include adequate venting, caution in patients with aortic insufficiency, and avoidance of intracardiac air. Adequate venting is routinely accomplished with a left ventricular vent placed via the right superior pulmonary vein. This technique has been described in detail. ${ }^{10}$ Patients with significant aortic insufficiency can pose a challenge, and a balance must be struck between adequate left ventricular venting and maintenance of adequate forward flow. We believe that most surgeons already possess the skills to perform the noncardioplegic, fibrillating technique without compromising patient outcomes or long-term graft patency.

\section{Study Limitations}

Limitations of this study include those inherent to any single-center retrospective analysis. We did not have a true control group because all patients with significant ascending aortic atheromatous disease were treated without clamping the aorta. In addition, this is a relatively small cohort of patients, and the overall stroke rate for patients undergoing CABG is known to be low. Given the historic increased incidence of neurologic complications for patients with ascending aortic disease, however, we think that the low stroke rate we achieved is likely significant. Also, we did not routinely have patients examined postoperatively by a neurologist nor was neurocognitive testing or magnetic resonance imaging performed. Any significant neurologic deficit, however, did trigger a neurology consult and further diagnostic imaging. We cannot rule out the possibility that our stroke rate was low because a disproportionate number of patients harbored grade III plaque versus more severe disease. Our original database did not allow us to subdivide groups on the basis of grade III, IV, or V plaque. We have since modified our data collection but do not have sufficient numbers to render meaningful analysis of these subgroups. Follow-up analysis should help clarify this question. We also only report data from the first 30 postoperative days. Longer-term neurologic outcomes may provide additional insights.

\section{CONCLUSIONS}

This review does suggest that clampless fibrillating heart surgery with circulatory arrest for proximal anastomoses is a safe and effective technique for revascularizing patients with significant ascending aortic disease who are otherwise at high risk for cerebral embolic complications.

\section{References}

1. van der Linden J, Hadjinikolaou L, Bergman P, Lindblom D. Postoperative stroke in cardiac surgery is related to the location and extent of atherosclerotic disease in the ascending aorta. J Am Coll Cardiol. 2001;38:131-5.

2. Bergman P, Hadjinikolaou L, Dellgren G, van der Linden J. A policy to reduce stroke in patients with extensive atherosclerosis of the ascending aorta undergoing coronary surgery. Interact Cardiovasc Thorac Surg. 2004;3:28-32.

3. van der Linden J, Bergman P, Hadjinikolaou L. The topography of aortic atherosclerosis enhances its precision as a predictor of stroke. Ann Thorac Surg. 2007; 83:2087-92.

4. Katz ES, Tunick PA, Rusinek H, Ribakove G, Spencer FC, Kronzon I. J Am Coll Cardiol. 1992;20:70-7.

5. Goto T, Baba T, Matsuyama K, Honma K, Ura M, Koshiji T. Aortic atherosclerosis and postoperative neurological dysfunction in elderly coronary surgical patients. Ann Thorac Surg. 2003;75:1912-8.

6. Roach GW, Kanchuger M, Mangano CM, Newman M, Nussmeier N, Wolman R, et al. N Engl J Med. 1996;335:1857-63. 
7. Akins CW. Noncardioplegic myocardial preservation for coronary revascularization. J Thorac Cardiovasc Surg. 1984;88:174-81.

8. Mills NL, Everson CT. Atherosclerosis of the ascending aorta and coronary artery bypass. J Thorac Cardiovasc Surg. 1991;102:546-53.

9. Bonchek LI, Burlingame MW, Vazales BE, Lundy EF, Gassman CJ. Applicability of Noncardioplegic coronary bypass to high-risk patients. J Thorac Cardiovasc Surg. 1992;103:230-7.

10. Lundy EF, Gassman CJ, Bonchek LI, Smith RG, Burlingame MW, Vazales BE. A simple and safe technique of left ventricular venting. Ann Thorac Surg. 1992;53: 1127-9.

11. Lee R, Matsutani N, Polimenakos AC, Levers LC, Lee M, Johnson RG. Preoperative noncontrast chest computed tomography identifies potential aortic emboli. Ann Thorac Surg. 2007;84:38-42.

12. Gold JP, Torres KE, Maldarelli W, Zhuralev I, Condit D, Wasnick J. Improving outcomes in coronary surgery: the impact of echo-directed aortic cannulation and perioperative hemodynamic management in 500 patients. Ann Thorac Surg. 2004;78:1579-85.

13. Mackensen GB, Ti LK, Phillips-Bute BG, Mathew JP, Newman MF, Grocott HP, and the Neurologic Outcome Research Group. Cerebral embolization during cardiac surgery: impact of aortic atheroma burden. Br J Anaesth. 2003;91:656-61.

14. Kolh PH, Torchiana DF, Buckley MJ. Atheroembolization in cardiac surgery: the need for preoperative diagnosis. J Cardiovasc Surg. 1999;40:77-81.

15. Royse AG, Royse CF, Ajani AE, Symes E, Maruff P, Karagiannis S, et al. Reduced neuropsychological dysfunction using epiaortic echocardiography and the exclusive Y graft. Ann Thorac Surg. 2000;69:1431-8.

16. Kouchoukos NT, Wareing TH, Daily BB, Murphy SF. Management of the severely atherosclerotic aorta during cardiac operations. J Card Surg. 1994;9:490-4.

17. Rokkas CK, Kouchoukos NT. Surgical management of the severely atherosclerotic ascending aorta during cardiac operations. Semin Thorac Cardiovasc Surg. 1998; 10:240-6.

18. Lev-Ran O, Ben-Gal Y, Matsa M, Paz Y, Kramer A, Pevni D, et al. 'No touch' techniques for porcelain ascending aorta: comparison between cardiopulmonary bypass with femoral artery cannulation and off-pump myocardial revascularization. J Card Surg. 2002;17:370-6.

19. Leachhe M, Carrier M, Bouchard D, Pellerin M, Perrault LP, Page P, et al. Improving neurologic outcome in off-pump surgery: the 'no-touch' technique. Heart Surg Forum. 2003;6:169-75.

20. Sakaguchi G, Tadamura E, Ohnaka M, Tambara K, Nishimura K, Komeda M. Composite arterial $\mathrm{Y}$ graft has less coronary flow reserve than independent grafts. Ann Thorac Surg. 2002;74:493-6.

21. Al-Ruzzeh S, Bustami M, Athanasiou T, George S, Ilsley C, Amrani M. A technical failure changes a $\mathrm{Y}$ graft into a $\mathrm{C}$-conduit causing steal syndrome. Asian Cardiovasc Thorac Ann. 2006;14:155-7.

22. Sugimura Y, Toyama M, Katoh M, Kotani M, Kato Y, Hisamoto K. Outcome of composite arterial Y-grafts in off-pump coronary artery bypass. Asian Cardiovasc Thorac Ann. 2011;19:119-22.

23. Barra JA, Bezon E, Mansourati J, Rukbi I, Mondine P, Youssef Y. Reimplantation of the right internal thoracic artery as a free graft into the left in situ internal thoracic artery (Y procedure). J Thorac Cardiovasc Surg. 1995;109: 1042-8.

24. Calafiore AM, Contini M, Vitolla G, Di Mauro M, Mazzei V, Teodori G, et al. Bilateral internal thoracic artery grafting: long term clinical and angiographic results of in situ versus y grafts. J Thorac Cardiovasc Surg. 2000;120:990-8.

25. Royse AG, Royse CF, Raman JS. Exclusive Y graft operation for multivessel coronary revascularization. Ann Thorac Surg. 1999;68:1612-8.

26. Hilker M, Arlt M, Keyser A, Schopka S, Klose A, Diez C, et al. Minimizing the risk of perioperative stroke by clampless off-pump bypass surgery: a retrospective observational analysis. J Cardiothorac Surg. 2010;5:14.

27. Emmert M, Seifert B, Wilhelm M, Grunenfelder J, Falk V, Salzberg S. Aortic notouch technique makes the difference in off-pump coronary artery bypass grafting. J Thorac Cardiovasc Surg. 2011;142:1499-506.

28. Biancari F, Mosorin M, Lahtinen J, Heikkinen J, Rasinaho E, Anttila V, et al. Results with the Heartstring anastomotic device in patients with diseased ascending aorta. Scand Cardiovasc J. 2006;40:238-9. 